\title{
OPTICALLY ACTIVE Si:Er LAYERS GROWN BY THE SUBLIMATION MBE METHOD
}

\author{
M. Stepikhova, A. Andreev, B. Andreev, Z. Krasil'nik, V. Shmagin \\ Institute for Physics of Microstructures, Russian Academy of Sciences \\ GSP-105, Nizhny Novgorod, Russia \\ V. Kuznetsov, R. Rubtsova
}

Nizhny Novgorod State University, Gagarin Avn. 23, Nizhny Novgorod, Russia

W. Jantsch, H. Ellmer, L. Palmetshofer, H. Preier

Institut für Halbleiterphysik, Johannes Kepler Universität, $4040 \mathrm{Linz}$, Austria

YU. KaRPoV

Institute for Chemical Problems of Microelectronics, Moscow, Russia

K. Piplits and H. Hutter

Institut für Analytische Chemie, Technische Universität Wien, Vienna, Austria

We report the first application of sublimation molecular beam epitaxy to grow uniformly and selectively doped Si:Er layers with Er concentration up to $5 \times 10^{18} \mathrm{~cm}^{-3}$. The Hall concentration of electrons is about $10 \%$ of total Er contents. The mobility is $300-400 \mathrm{~cm}^{2} \mathrm{~V}^{-1} \mathrm{~s}^{-1}$ at $300 \mathrm{~K}$. All samples exhibit photoluminescence at $1.537 \mu \mathrm{m}$ up to $100-140 \mathrm{~K}$.

PACS numbers: $81.15 . \mathrm{Hi}$

\section{Introduction}

Erbium in silicon has attracted considerable interest because of its potential to give high-efficiency sharp luminescence at $1.54 \mu \mathrm{m}$, the optimum wavelength for optical telecommunication systems. The development of Er-based devices depends on the ability to incorporate optically active $\mathrm{Er}^{3+}$ ions efficiently into the host material. A high volume density, at least about $10^{18} \mathrm{~cm}^{-3}$ of Er ions [1], is required to fabricate technologically useful devices and to obtain sufficient luminescence intensity. One particularly attractive way to incorporate $\mathrm{Er}$ ions into $\mathrm{Si}$ is via molecular beam epitaxy $(\mathrm{MBE})$ at low temperature $\left(500-600^{\circ} \mathrm{C}\right)[2,3]$. 
In this article we report for the first time on the application of sublimation MBE (SMBE) to grow Si layers with a high concentration of erbium and the investigation of their properties. This method allows to grow uniformly doped monocrystalline layers of $\mathrm{Si}$, as well as structures with a specified doping profile, with the concentration of the main electrically active impurities as $\mathrm{Sb}, \mathrm{P}, \mathrm{Al}, \mathrm{As}$ in the range $2 \times 10^{13}-4 \times 10^{20} \mathrm{~cm}^{-3}[4,5]$. Moreover, the impurity segregation in SMBE can be avoided without special contrivances [5]. In the SMBE method the role of the Si source and the doping source is played by the plate of $\mathrm{Si}$, doped by the desired element, here in particular Er. The doping level in the SMBE layers is determined by the source impurity concentration, the growth velocity and the substrate temperature $[4,5]$.

\section{Experiment}

The Si:Er layers were grown in a vacuum of $2 \times 10^{-7}$ mbar on $\operatorname{Si}(100) p$-type substrates $(\rho \approx 10 \Omega \mathrm{cm})$. Si plates doped with $\mathrm{Er}$ up to $\approx 10^{21} \mathrm{~cm}^{-3}$ were used as a source for both the $\mathrm{Si}$ and $\mathrm{Er}$ vapors. The $\mathrm{Si}$ source and the substrate were heated by electrical current. The substrate temperature was $400-700^{\circ} \mathrm{C}$. After the growth process, the structures (except for the selectively doped structures) were annealed in a vacuum chamber at $900^{\circ} \mathrm{C}$ for $30 \mathrm{~min}$. The thickness of the $\mathrm{Si}: \mathrm{Er}$ layers varied from 0.2 to $3 \mu \mathrm{m}$.

The $\mathrm{Er}$ and $\mathrm{O}$ profiles and the $\mathrm{Si}$ crystal quality were characterized with secondary ion mass spectrometry (SIMS) and Rutherford backscattering spectroscopy (RBS). The profiles of free carriers at room temperature were determined by the Hall and $C-V$ measurements. The electrically active defects in the layers were detected using deep level transient spectroscopy (DLTS) at 50-350 K. The photoluminescence (PL) spectra were measured in the range of $4.2-300 \mathrm{~K}$ using BOMEM DA3.36 and DA8 Fourier spectrometers with $\mathrm{Ar}^{+}(\lambda=514.5 \mathrm{~nm})$ and $\mathrm{Kr}^{+}(\lambda=647 \mathrm{~nm})$ lasers as excitation sources.

\section{Results and discussion}

Figure 1 shows the SIMS profiles of Er and O in the SMBE film grown at $600^{\circ} \mathrm{C}$. The Er and $\mathrm{O}$ concentrations are distributed rather homogeneously with values of $5 \times 10^{18}$ and $4 \times 10^{19} \mathrm{~cm}^{-3}$, respectively. This fact confirms that both $\mathrm{Er}$ and $O$ segregation on a growth surface is insignificant. Decreasing the substrate temperature down to $400^{\circ} \mathrm{C}$ does not cause any significant changes in the $\mathrm{Er}$ and O profiles. On the other hand, enhancing the growth temperature up to $700^{\circ} \mathrm{C}$ leads to Er segregation, seen by an inhomogeneous Er profile. Here the oxygen can be incorporated in the samples from the residual gas of vacuum chamber or from Si:Er source.

RBS measurements were performed for $\mathrm{Si}$ :Er structures grown at $600^{\circ} \mathrm{C}$. The profiling results (random conditions) are close to those shown in Fig. 1. The channeling has been performed for the $\langle 100\rangle$ axis and the $\{110\}$ and $\{100\}$ planes. The minimum channeling yield in the Si part of the spectra (axial case) is $\chi_{\min }=5 \%$, in the planar case $27 \%$ and $35 \%$ respectively. This demonstrates the high crystalline quality of the samples. The Er yields show the same angular dependence as $\mathrm{Si}$ yields in all measured directions, which seems to indicate that 


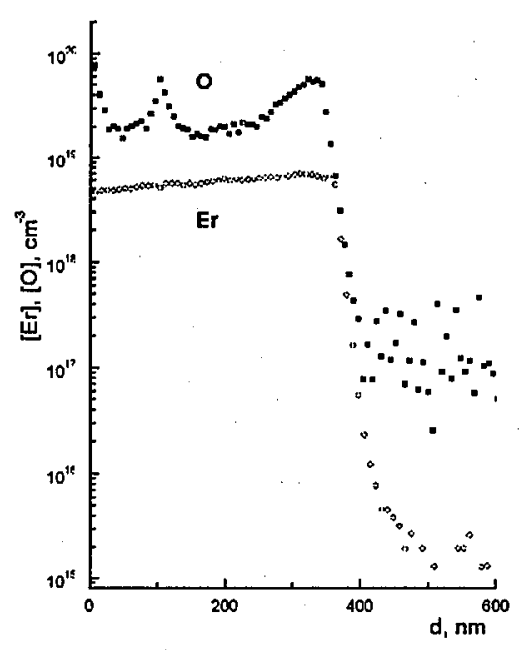

Fig. 1. Er and $\mathrm{O}$ profiles (SIMS data) for Er-doped film grown on $\operatorname{Si}(100)$ at $600^{\circ} \mathrm{C}$. The depth is counted from the outer sample surface.

erbium is incorporated both at substitutional and tetrahedral interstitial ( $T_{d}$ symmetry) lattice sites. Selective etching of Si:Er layers $(d \approx 3 \mu \mathrm{m})$ does not reveal any packing defects and additional dislocations as compared to the substrate.

A selectively doped Si:Er structure comprising three Er doped layers was grown taking advantage of the fact that only insignificant Er segregation occurs at the growth surface. The layer growth temperatures were 580,440 , and $580^{\circ} \mathrm{C}$, the expected thicknesses $-2,1$, and $40 \mathrm{~nm}$ respectively (from the outer surface to the substrate). The Er-doped layers were separated by undoped layers $(\approx 1,0.5$, and $0.5 \mu \mathrm{m}$ in thickness) grown from a high resistivity $n$-Si source. The $C-V$ profile (Fig. 2) shows three sharp peaks corresponding to the selectively doped layers. The carrier concentration in the narrower layers was evaluated by integrating $C(V)$ results using the nominal layer thicknesses giving $1.4 \times 10^{18}$ and $2.4 \times 10^{18} \mathrm{~cm}^{-3}$. These values are close to those for uniformly doped reference layers grown at 600 and $400^{\circ} \mathrm{C}$. The selective etching revealed neither packing defects nor additional dislocations with respect to the substrate.

All the grown layers show $n$-type conductivity, independent of the substrate properties and the heat treatment conditions (with $900^{\circ} \mathrm{C}$ annealing or without it). Hall measurements gave concentrations of $4 \times 10^{17}$ and $2.5 \times 10^{17} \mathrm{~cm}^{-3}$ and mobilities of 340 and $370 \mathrm{~cm}^{2} \mathrm{~V}^{-1} \mathrm{~s}^{-1}$ for the uniformly doped layers grown at 400 and $600^{\circ} \mathrm{C}$, respectively. The electrical activity of $\mathrm{Er}$ in these layers is about $10 \%$, as in implanted structures [6]. SIMS and $C-V$ profiles were close to each other for all grown structures, thus confirming the correlation of donor activity with $\mathrm{Er}$ atoms.

We report here also the first DLTS data for SMBE Si:Er layers (and for MBE layers also). The levels detected (with activation enthalpies of $0.17,0.26,0.32$, and $0.44 \mathrm{eV}$ relative to the bottom of the conduction band) are close to those seen in 


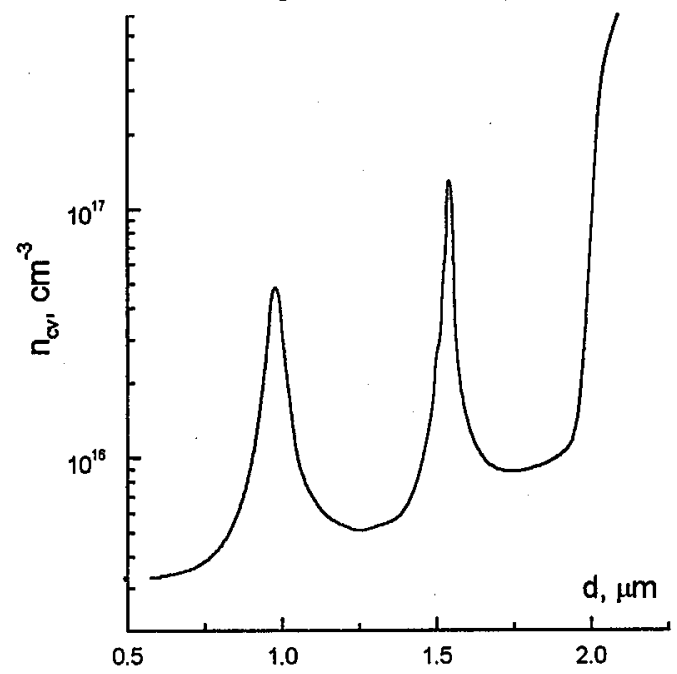

Fig. 2. $C-V$ profile for a selectively doped $\mathrm{Si}$ structure. The depth is counted from the outer sample surface.

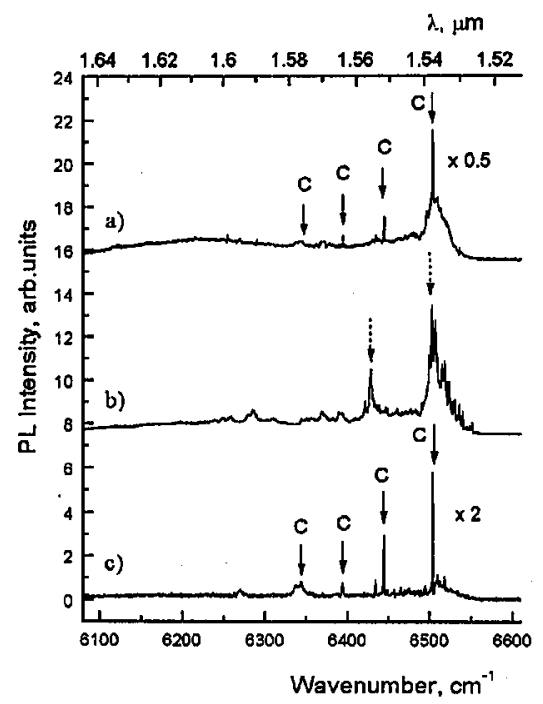

Fig. 3. PL spectra of SMBE grown Si:Er. The curves $a$ and $b$ were obtained for the samples grown at 600 and $400^{\circ} \mathrm{C}$ respectively, $c-$ for selectively doped structure. The PL signal has been scaled by a factor of $2(c)$ and $0.5(a)$. The spectral resolution is $0.5 \mathrm{~cm}^{-1}$. The sample temperature is $4.2 \mathrm{~K}$.

Er-implanted Si. The intensive lines with energies more than $0.48 \mathrm{eV}$, typical of implanted layers $[7,8]$, are absent in our spectra. As the PL signal is sufficiently intense in both SMBE and implanted structures we suppose that these levels are not responsible for exciting the PL in Si:Er structures. We suppose that they correspond to complicated defects arising from the Er implantation process. 
Figure 3 shows PL spectra of the uniformly doped samples grown at $600^{\circ} \mathrm{C}(a)$ and $400^{\circ} \mathrm{C}(b)$ and the selectively doped structure $(c)$, respectively. All spectra exhibit a sharp peak at $1.537 \mu \mathrm{m}$. For the layer grown at $600^{\circ} \mathrm{C}$ an optically active $\mathrm{Er}$ center is observed with its main lines due to the optical transitions ${ }^{4} I_{13 / 2} \rightarrow{ }^{4} I_{15 / 2}$ at $6504.1,6444.8,6394.1$, and $6344.6 \mathrm{~cm}^{-1}$ (labeled "C" in Fig. 3a). Taking into account the number of lines [7], their positions and RBS channeling data, this seems to indicate $\mathrm{Er}^{3+}$ ion to be in the site with tetrahedral symmetry.

The PL spectrum of the sample grown at $400^{\circ} \mathrm{C}$ is more complicated. It includes two intense lines at 6502.9 and $6429.2 \mathrm{~cm}^{-1}$ and a series of extremely narrow lines at $6506.8 \div 6551.4 \mathrm{~cm}^{-1}$. This indicates the presence of some optically active Er centers with lower symmetry, possibly complicated Er-O complexes [7].

The spectrum shown in Fig. 3c is close to that in Fig. 3a. The other Er-related PL series and Si defect-related lines were not observed.

The temperature dependencies of $\mathrm{PL}$ intensity for structures uniformly doped at 400 and $600^{\circ} \mathrm{C}$ show the $\mathrm{PL}$ temperature quenching of above 90 and $140 \mathrm{~K}$, respectively. For the $600^{\circ} \mathrm{C}$ structure the temperature dependence of $\mathrm{PL}$ shows two activation energies of $\approx 13$ and $60 \mathrm{meV}$. The first value is relevant for the temperature range of $30-80 \mathrm{~K}$ and is close to results for implanted $[7,9]$ and MBE [10] layers. The latter value characterizes the temperature regime of $T>80 \mathrm{~K}$ and is smaller as compared to [7] $(80-100 \mathrm{meV})$.

\section{Conclusion}

The uniformly and selectively doped Si:Er structures are grown at $400-600^{\circ} \mathrm{C}$ by SMBE for the first time with a high concentration of $\mathrm{Er}$ and $\mathrm{O}$ (up to $5 \times 10^{18}$ and $4 \times 10^{19} \mathrm{~cm}^{-3}$ respectively). All structures exhibit photoluminescence close to $1.54 \mu \mathrm{m}$ up to $100-140 \mathrm{~K}$. Optically active Er centers with their main lines at $6504.1,6444.8,6394.1$, and $6344.6 \mathrm{~cm}^{-1}$ were observed in the PL spectra of most grown layers. PL and RBS data seem to suggest that this center is related to $\mathrm{Er}^{3+}$ ion in the site with tetrahedral symmetry.

According to Hall effect measurements the electron concentration is $\approx 10 \%$ of the total Er concentration and the mobility $-300-400 \mathrm{~cm}^{2} \mathrm{~V}^{-1} \mathrm{~s}^{-1}$ at room temperature. DLTS data show defects with an ionization energy $E_{\mathrm{i}} \leq 0.48 \mathrm{eV}$.

This work was partially supported by RFBR (grants \#\#98-02-16619, 96-02-19283), Russian Program "Fundamental Spectroscopy" (grant \#08.02.043) and Gesellschaft für Mikroelektronik, Vienna. One of us (H.E.) wants to thank the Jubiläumsfonds der Österreichischen Nationalbank (contract \#4680) for financial support.

\section{References}

[1] Y.-H. Xie, E.A. Fitzgerald, Y.J. Mii, J. Appl. Phys. 70, 3223 (1991).

[2] J. Stimmer, A. Reittinger, J.F. Nützel, G. Abstreiter, H. Holzbrecher, Ch. Buchal, Appl. Phys. Lett. 68, 3290 (1996).

[3] R. Serna, Jung H. Shin, M. Lohmeier, E. Vlieg, A. Polman, P.F.A. Alkemade, J. Appl. Phys. 79, 2658 (1996).

[4] V.P. Kuznetsov, A.Yu. Andreev, O.A. Kuznetsov, L.E. Nikolaeva, T.M. Zotova, N.V. Gudkova, Phys. Status Solidi A 127, 371 (1991). 
[5] V.P. Kuznetsov, A.Yu. Andreev, N.A. Alyabina, Elektronnaya Promyshlennost' 9, 57. (1990).

[6] L. Palmetshofer, Yu. Suprun-Belevich, M. Stepikhova, Nucl. Instr. Methods Phys. Res. B 127/128, 479 (1997).

[7] H. Przybylinska, W. Jantsch, Yu. Suprun-Belevitch, M. Stepikhova, L. Palmetshofer, G. Hendorfer, A. Kozanecki, R.J. Wilson, B.J. Sealy, Phys. Rev. B 54, 2532 (1996).

[8] J.L. Benton, J. Michel, L.C. Kimerling, D.C. Jacobson, Y.-H. Xie, D.J. Eaglesham, E.A. Fitzgerald, J.M. Poate, J. Appl. Phys. 70, 2667 (1991).

[9] S. Coffa, G. Franzo, F. Priolo, A. Polman, R. Serna, Phys. Rev. B 49, 16313 (1994).

[10] H. Efeoglu, J.H. Evans, T.E. Jackman, B. Hamilton, D.C. Houghton, J.M. Langer, A.R. Peaker, D. Perovic, I. Poole, N. Ravel, P. Hemment, C.W. Chan, Semicond. Sci. Technol. 8, 236 (1993). 